\title{
Publicidade e infância: relato de uma experiência de literacia publicitária com crianças
}

Pâmela Saunders Uchôa Craveiro

Doutora em Comunicação pela Universidade de Vigo, Espanha, com pós-doutorado na Universidade Federal Fluminense (UFF)

E-mail: pamela_uchoa@yahoo.com.br

Resumo: Este artigo tem como objetivo apresentar e discutir uma experiência de oficina de leitura crítica com crianças de 10 e 11 anos. Experiência esta pensada e articulada à luz dos pressupostos de pesquisa-intervenção e a partir das contribuições de alguns autores a respeito da literacia publicitária, especialmente Malmelin, em 2010; Baker, em 2008; e Machado, Burrowes e Rett em 2017. O estudo evidencia a importância de construir canais de diálogo para que as crianças possam expressar o que pensam sobre a publicidade e, sobretudo, possam aprofundar seu senso crítico sobre as relações de consumo que têm pautado a sociedade.

Palavras-chave: publicidade; infância; literacia publicitária.
Abstract: This article aims to present and discuss a workshop experience of advertising literacy with children aged 10 and 11 years. This experience is thought and articulated in the light of the presuppositions of the intervention research and from the contributions of some authors regarding advertising literacy, especially Malmelin in 2010, Baker in 2008, Machado, Burrowes and Rett in 2017. The study highlights the importance of building channels of dialogue so that children can express what they think about advertising and, above all, they can deepen their critical sense about consumer relations that have guided society.

Keywords: advertising; childhood; advertising literacy. 
1. BRASIL. Conselho Nacional dos Direitos da Criança e do Adolescente. Resolução no 163, de 13 de março de 2014. Dispõe dobre a abusividade do direcionamento de publicidade e de comunicação mercadológica à criança e ao adolescente. Diário Oficial [da] República Federativa do Brasil, Brasília, DF, 4 abr. 2014. Disponível em: <http:// www.crianca.mppr.mp.br/ arquivos/File/legis/conanda/conanda_resolucao_163_publicada.pdf>. Acesso em: 3 jan. 2018.

2. $\mathrm{SCHOR}$, Juliet B. Nascidos para comprar: uma leitura essencial para orientarmos nossas crianças na era do consumismo. São Paulo: Gente, 2009

3. STEINBERG, Shirley; KINCHELOE, Joe (orgs.) Cultura infantil: a construção corporativa da infância. Rio de Janeiro: Civilização Brasileira, 2004. comunicação \& educação • Ano XXIII • número 1 • jan/jun 2018

\section{INTRODUÇÃO}

A relação entre publicidade e infância é uma temática que, sobretudo nos últimos dez anos, tem suscitado interesse nas mais diversas áreas da sociedade brasileira. No campo legislativo, devem ser reconhecidos os avanços na questão dos esforços em regular a publicidade dirigida ao público infantil. Desde o ano de 2014, contamos com a Resolução nº 163 do Conselho Nacional dos Direitos da Criança e do Adolescente (Conanda) ${ }^{1}$, que declara ser abusiva e ilegal toda e qualquer comunicação mercadológica direcionada a crianças, estabelecendo de forma clara quais as ações devem ser evitadas pelas empresas ao produzirem suas estratégias promocionais. Entretanto, na prática, temos um cenário em que inúmeras empresas ainda direcionam sua comunicação mercadológica ao público infantil.

À espera da efetivação do direito à proteção das crianças diante do caráter abusivo da publicidade direcionada a elas, a alfabetização midiática emerge como requisito fundamental para contribuir na formação de crianças críticas às relações de consumo que permeiam nossa sociedade. Urge desenvolver uma alfabetização midiática para estabelecer níveis aceitáveis de literacia e promover a formação de cidadãos com um marcado caráter crítico-construtivo. Nesse sentido, convém desvelar a mensagem publicitária de modo a oportunizar competências às crianças, para que possam refletir sobre as estratégias publicitárias que invadem seu cotidiano.

Diante desse panorama, este artigo busca apresentar e problematizar uma experiência de oficina de leitura crítica da publicidade com um grupo de crianças de 10 e 11 anos. O texto está estruturado em quatro tópicos, além desta introdução. Nos três primeiros, é desenvolvida uma discussão mais teórica, que se inicia com breve contextualização da publicidade infantil no cenário atual, prosseguindo com uma reflexão sobre literacia midiática e se encerra abordando a literacia publicitária em específico. Posteriormente, a proposta de oficina de leitura crítica é apresentada e discutida. Por fim, são comentadas as conclusões e contribuições do estudo, bem como as perspectivas de trabalhos futuros.

\section{CONTEXTUALIZAÇÃO DA PUBLICIDADE INFANTIL NO CENÁRIO CONTEMPORÂNEO}

O marketing e a publicidade têm alterado fundamentalmente a experiência da infância ao penetrar nas escolas, na família e nas brincadeiras infantis. Nesse cenário, como aponta $\mathrm{Schor}^{2}$, a criança converte-se em um elo entre mercado e lares, entre anunciantes e famílias. Vivenciamos o que Steinberg e Kincheloe ${ }^{3}$ chamam de produção corporativa da infância, em que os interesses comerciais são, muitas vezes, mais valorizados que o bem-estar. Ou seja, a criança tende a ser percebida pelas marcas como novo consumidor e, desse modo, é negligenciada sua condição de indivíduo que vivencia uma fase peculiar de desenvolvimento. 
Em virtude dos múltiplos fatores tecnológicos, comerciais e pedagógicos que perpassam a publicidade na atualidade, há uma dificuldade em se precisar uma definição para o termo publicidade infantil. É o que acastelam os pesquisadores Guedes e Covaleski ${ }^{4}$. De acordo com esses autores, a publicidade que dialoga com a criança ultrapassa as estratégias comunicacionais de produtos/ serviços experienciados prioritariamente pelo público infantil. Nessa perspectiva, um anúncio de produtos/serviços para adultos, ao usar elementos facilmente vinculados ao mundo infantil e/ou quando é veiculado em espaços reconhecidos socialmente como para crianças (canais e sites infantis, por exemplo) também pode atingir esse público.

Diante do caráter revolucionário e sem precedentes das transformações tecnológicas e culturais que a era digital trouxe para o mundo, presenciamos uma reconfiguração do mercado publicitário que tem contribuído para tornar ainda mais complexa a relação entre infância e publicidade. As mudanças ocorridas no ecossistema midiático vão muito além da visível multiplicidade de plataformas e suportes de comunicação. Conforme Martí-Parreño ${ }^{5}$, elas dizem respeito também às novas formas de consumo dos meios pelos usuários - por exemplo, o uso simultâneo de diferentes meios, a configuração de suas próprias faixas de horário no consumo midiático, a criação e a difusão de seus próprios conteúdos, entre outros aspectos.

Covaleski ${ }^{6}$ defende a existência de um processo de hibridização da publicidade com outros meios comunicativos. Segundo o autor: "no processo de transição comunicacional em curso, à publicidade - cuja função essencial é anunciar - somaram-se funções derivadas, de ora entreter, ora interagir". Nesse âmbito, anteriormente especialista em interromper o conteúdo para chamar atenção, agora a publicidade tende a ser mais "bem aceita" pelo consumidor contemporâneo quanto menos se parece consigo mesma, ou seja, quanto menos usa os elementos tradicionais constituintes do discurso publicitário convencional. Desse modo, crescentemente aparece camuflada de entretenimento, embora não destituída de sua função persuasiva, ainda que muitas vezes dissimulada.

Em um trabalho anterior ${ }^{7}$, mapeamos estratégias e formatos recorrentemente utilizados para dialogar com as crianças e constatamos essa tendência à hibridização entre o que é e o que não é publicidade e entretenimento, bem como uma propensão ao oferecimento de conteúdo midiático sem apelo evidenciado ao consumo do produto ou da marca que o patrocina. Isso tem implicado um embaçamento das fronteiras entre o que é e o que não é publicidade, o que pode dificultar a identificação do conteúdo publicitário e de sua intenção persuasiva por parte do público infantil.

Nessa conjuntura em que se percebe uma tendência a práticas de publicidade hibridizadas com conteúdo informacional e/ou de entretenimento, e à espera de uma regulamentação mais precisa e de melhores éticas e compromissos corporativos em relação à publicidade infantil, evidencia-se o papel essencial da educação para a recepção crítica da publicidade.
4. GUEDES, Brenda; COVALESKI, Rogério. Publicidade e infância: traços de uma cultura infantil do consumo. In: ALCÂNTARA, Alessandra; GUEDES, Brenda. Culturas infantis do consumo: práticas e experiências contemporâneas. São Paulo: Pimenta Cultural, 2014, p. 153-177.

5. MARTÍ-PARREÑO, Jose. Marketing y videojuegos: product placement, in-game advertising y advergaming. Madrid: Esic, 2010.

6. COVALESKI, Rogério. Conteúdo de marcas e entretenimento: narrativas híbridas. Comunicação, Mídia, Consumo, São Paulo, v. 12, n. 34, p. 107-123, 2015b, p. 14.

7. CRAVEIRO, Pâmela Saunders Uchôa. Publicidade e infância: estratégias persuasivas direcionadas para crianças na internet. Culturas Midiáticas, João Pessoa, v. 9, n. 1, p. 16-32, 2016. 
8. FANTIN, Monica. Mídia-educação: aspectos históricos e metodológicos. Olhar de Professor, Ponta Grossa, v. 14, n. 1, p. $27-40,2011$, p. 28

9. COVALESKI, Rogério. O exercício da cidadania na literacia das novas narrativas publicitárias. In: PEREIRA, Sara; TOSCANO, Margarida (eds.). Literacia, media e cidadania: livro de atas do $3^{\circ}$ congresso. Braga: CECS, 2015a, p. 456-467.

10. BÉVORT, Evelyne; BELLONI, Maria Luiza.

Mídia-educação: conceito, histórias e perspectivas. Educação e Sociedade, Campinas, v. 30, n. 109 p. 1081-1102, set./dez. 2009

11. FANTIN, Monica, op. cit.

12. SETTON, Maria da Graça. Mídia e educação. São Paulo: Contexto, 2015, p. 7.

13. ABREU, Belinha S. de. Media literacy, social networking, and the Web 2.0 environment for the K-12 educator. New York: Peter Lang, 2011. comunicação \& educação • Ano XXIII • número 1 • jan/jun 2018

\section{LITERACIA MIDIÁTICA: APROPRIAÇÃO CRÍTICA E CRIATIVA DAS MÍDIAS}

A discussão em torno da necessidade de inclusão do estudo das mídias e das práticas comunicativas na educação vem sendo feita há alguns anos. Fantin ${ }^{8}$ aponta que desde a década de 1980 já se enfatizava o papel da escola na produção social da comunicação emancipatória. Da preocupação com as mediações escolares e da premissa de que "a comunicação é imprescindível para a educação, pois toda prática educativa é uma prática também comunicativa”, tem se configurado um prolífero campo teórico-prático: o da educação-comunicação.

Conforme Covaleski ${ }^{9}$, novos vieses investigativos têm se consolidado à luz da interface entre os campos da educação e da comunicação. No Brasil, muitos são os termos dados para esses novos vieses. Literacia midiática, mídia-educação, educomunicação, pedagogia da comunicação e leitura crítica dos meios são alguns deles. Essas distintas designações são resultantes de um campo relativamente novo e que, segundo Bèvort e Belloni ${ }^{10}$, tem encontrado algumas dificuldades de consolidação. Ademais, correspondem a múltiplas concepções e enfoques distintos usados pelos variados especialistas que vêm se dedicando a refletir sobre os temas inseridos nessa interseção entre educação e comunicação.

Apesar de não haver consenso quanto ao termo usado, de acordo com Fantin $^{11}$, percebe-se a existência de uma concordância quanto aos objetivos de quem trabalha (no campo da teoria e da prática) com a educação para e/ou com as mídias: a formação de um indivíduo ativo, crítico e criativo em relação às tecnologias de informação e comunicação. Sendo assim, trabalha-se com a defesa da ideia de que não pode haver cidadania sem uma apropriação crítica e criativa das mídias.

No contexto da relação do fenômeno das mídias com a educação, considera-se o papel educativo que essas exercem no mundo contemporâneo ao funcionarem como difusoras de padrões, valores, normas de comportamento e referências identitárias. Em consonância com Setton ${ }^{12}$, neste artigo, por mídia entendemos "todo o aparato simbólico e material relativo à produção de mercadorias de caráter cultural". Desse modo, abrange a todo o universo de mensagens difundidas com auxílio de algum suporte material, veiculadas sistematicamente por instituições de diversos setores - seja fonográfico, televisivo, editorial, cinematográfico, radiofônico ou publicitário. Nesse âmbito, como acastela $\mathrm{Abreu}^{13}$, quando se fala em apropriação crítica e criativa das mídias, contempla-se a capacidade do indivíduo de ter pensamento e letramento críticos diante de todos os textos midiáticos do século XXI, por meio de competências em literacia global, cívica, tecnológica e de informação.

Entre esses textos midiáticos do século XXI, certamente encontra-se o conteúdo publicitário. Do mesmo modo que se impulsiona a leitura crítica e a produção transformadora de conteúdos veiculados pelo jornalismo, pelo cinema, por novelas etc., deve-se estimular o desenvolvimento de capacidades de literacia direcionadas especificamente para a publicidade. Essa necessidade 
fica ainda mais evidente perante constatações, como a de Malmelin $^{14}$, de que ainda são raros os projetos que se dedicam ao fomento de noções de literacia voltadas especialmente para a comunicação mercadológica.

\section{LITERACIA PUBLICITÁRIA: ORGANIZANDO, AVALIANDO E COMPREENDENDO AS MENSAGENS MERCADOLÓGICAS}

Mensagens de marketing e publicidade têm ocupado cada vez mais a vida diária do consumidor contemporâneo. De acordo com Malmelin ${ }^{15}$, os consumidores necessitam de competências em literacia publicitária para que sejam capazes de organizar, avaliar e compreender essas mensagens mercadológicas a que são expostos. O primeiro passo para isso, segundo o autor, é ter consciência do imenso volume de anúncios recebidos e da influência que a publicidade exerce em seu cotidiano.

Malmelin considera a publicidade como uma forma de comunicação peculiar e que, portanto, requer habilidades específicas de literacia que diferem daquelas necessárias para outras formas de comunicação midiática. Com o intuito de diminuir a lacuna existente no estudo e na prática de literacia publicitária, o autor propõe um modelo baseado em quatro dimensões: informacional, estética/ visual, retórica e promocional. A literacia informacional diz respeito à capacidade de avaliar a credibilidade e a validade da informação presente no discurso publicitário. A estética/visual refere-se à habilidade de apreciar e problematizar a escolha dos elementos estéticos e de expressão artística usados em um anúncio de publicidade, enquanto a retórica concerne à competência de compreender e avaliar criticamente variadas estratégias de persuasão utilizadas na publicidade. Por fim, a literacia promocional está relacionada à capacidade de reconhecer diferentes formas de comunicação mercadológica no cenário contemporâneo de convergência midiática, dessa forma, compreendendo diferentes tipos de parcerias comerciais e colaborações na indústria dos meios de comunicação.

A esse modelo desenvolvido por Malmelin por meio de suas impressões resultantes de experiências de oficinas com jovens no contexto do Observatório da Publicidade Expandida ${ }^{16}$, Burrowes ${ }^{17}$ propõe o acréscimo de uma nova dimensão da alfabetização publicitária: a performática ou pragmática. Esse aspecto abrangeria a habilidade de perceber e avaliar a conexão ou distância entre as promessas das marcas e o que elas de fato entregam, considerando o âmbito das práticas sociais diárias da empresa nas áreas ambiental e social, além do campo psicológico.

Machado, Burrowes e Rett $^{18}$ ressaltam que tais habilidades constitutivas da literacia publicitária já estão presentes nos indivíduos inseridos na sociedade de consumo, podendo variar de acordo com idade, nível de instrução, acesso à diversidade de mídias e, inclusive, grau de atenção empenhado nos vários momentos de exposição diária à publicidade. Nesse sentido, para as autoras,
14. MALMELIN, Nan-

do. What is advertising literacy? Exploring the dimensions of advertising literacy. Journal of Visual Literacy, Abingdon, v. 29, n. 2 , p. 129-142, 2010.

15. Ibidem.

16. Projeto de extensão coordenado pela professora Patricia Burrowes (Universidade Federal do Rio de Janeiro) e que tem como objetivo contribuir com a educação crítica em relação à publicidade.

17. BURROWES, Patricia. Observatory of expanded advertising: an experience with advertising literacy workshops in Rio de Janeiro, Brazil. In: CONGRESSO DA INTERNATIONAL ASSOCIATION FORMEDIA AND COMMUNICATION RESEARCH，2017, Cartagena. Anais.. Cartagena: IAMCR, 2017.)

18. MACHADO, Monica; BURROWES, Patricia; RETT, Lucimara. Para ler a publicidade expandida: em favor da literacia midiática dos discursos das marcas. In: ENCONTRO ANUAL DA COMPÓS, 26., 2017, São Paulo. Anais.. São Paulo: Associação Nacional dos Programas de Pós-Graduação em Comunicação, 2017, p. 13. 
19. COVALESKI, Rogério, op. cit., $2015 a$.

20. BAKER, Frank W Political campaigns and political advertising: a media literacy guide. Westport: Greenwood Press, 2008, p. 464.

21. COVALESKI, Rogério, op. cit., $2015 \mathrm{a}$.

22. CAstro, Lúcia Rabello de; BESSET, Vera Lopes. Pesquisa-intervenção na infância e juventude: construindo caminhos. In: CASTRO, Lúcia Rabello de; BES-

SET, Vera Lopes (orgs.).

Pesquisa-intervenção na infância e juventude. Rio de Janeiro: Trarepa/ Faperj, 2008, p. 9-12.

23. Crianças com essa idade, de acordo Montigneaux (2003), tendem a apresentar senso crítico mais acentuado e incorporam conceitos com mais facilidade. comunicação \& educação • Ano XXIII • número 1 • jan/jun 2018

“a produção e divulgação de um modelo de leitura crítica serviria de eixo em torno do qual se poderia concentrar e organizar um saber disperso, favorecendo seu desenvolvimento e facilitando seu compartilhamento".

Covaleski ${ }^{19}$, ao avaliar o papel da mídia a partir do ponto de vista das narrativas publicitárias, assegura que a publicidade, para ser analisada, necessita ser desconstruída. Desse modo, seria possível estudar os elementos que a compõem e compreender como foi construída. Para promover a literacia midiática de jovens cidadãos, no que concerne ao conteúdo publicitário, o autor reúne alguns princípios fundamentais com base nas proposições de Baker $^{20}$. São eles:

todas as mensagens mediáticas são criteriosamente construídas; as mensagens são construídas usando uma linguagem criativa e persuasiva seguindo um conjunto próprio de regras, técnicas e linguagens; pessoas-alvo das mensagens experimentam o mesmo conteúdo mediático de modo distinto; os media têm valores e pontos de vista próprios e que são incorporados no conteúdo que veiculam; a maioria das mensagens mediáticas é organizada para obtenção de lucro e/ou poder.

Por sua motivação essencialmente comercial, ou seja, seu interesse em persuadir ao consumo, a publicidade é compreendida por Covaleski ${ }^{21}$ como uma das áreas mais controversas do campo da comunicação midiática, inclusive por dentre seus públicos estarem crianças, as quais não apresentam a devida capacidade cognitiva para interpretação crítica de suas mensagens. Nesse contexto, como trabalhar a literacia publicitária com crianças? Na seção seguinte discutiremos uma possibilidade desenvolvida com um grupo de crianças de idade entre 10 e 11 anos.

\section{CONSTRUINDO UMA PROPOSTA DE LEITURA CRÍTICA DA PUBLICIDADE COM CRIANÇAS}

Este artigo apresenta um recorte de uma pesquisa de pós-doutorado, a qual busca analisar práticas de multiletramento de crianças sobre a publicidade. Este texto, em específico, tem como foco apresentar e discutir uma proposta de oficina de leitura crítica trabalhada com crianças. Essa proposta foi construída articulada com as contribuições dos autores discutidos nos tópicos anteriores e à luz dos pressupostos da pesquisa-intervenção, em conformidade com Castro e Besset ${ }^{22}$.

A oficina foi composta pelas seguintes atividades: (I) criando um anúncio, (II) desmistificando a publicidade, e (III) analisando a publicidade: o que esse anúncio diz?. O tempo previsto para cada dinâmica foi de 30 minutos, somando-se um intervalo de 15 minutos entre a segunda e a terceira atividade. Participaram da oficina 6 crianças (3 meninos e 3 meninas), com idade entre 10 e 11 anos $^{23}$. As atividades ocorreram no Colégio Universitário Geraldo Reis, localizado em Niterói-RJ, conveniado à Universidade Federal Fluminense (UFF). 


\subsection{Brincando de criar um anúncio}

A atividade "criando um anúncio" consistiu em disponibilizar uma caixa de papelão contendo vários objetos diferentes, organizar as crianças em duplas e solicitar que cada uma escolhesse algo da caixa para que fosse o produto do anúncio publicitário que iriam construir e, posteriormente, apresentar para o restante do grupo. Para a criação, foram disponibilizadas canetas, lápis de cor e papéis. Contudo, as crianças foram avisadas de que poderiam usar a criatividade e criar um anúncio para ser divulgado em qualquer mídia (televisão, rádio, internet, jornal, revista etc.) e para qualquer público (crianças, jovens, adultos, mulheres, homens etc.). Para isso, poderiam usar o material disponibilizado para fazer um anúncio impresso ou até mesmo realizar uma encenação de um vídeo para televisão, por exemplo. O tempo da dinâmica foi dividido em 20 minutos para criação do anúncio e 10 minutos para apresentação.

Boneco da franquia Star Wars, óculos de sol e pinguim de pelúcia foram os objetos escolhidos pelas três duplas para "brincar" de anunciar. Todas as crianças decidiram apresentar seus anúncios em formato de dramatização, mas nenhuma deixou claro em que meio ou formato pretendiam veiculá-los nem a que público pretendia direcioná-lo. A seguir, temos alguns trechos das dramatizações de cada dupla:

Dupla 1: Esse boneco é muito barato. Você pode comprar para você e se divertir em casa por $\mathbf{R} \$ 10,99$. [Ao terminar de falar, a criança faz barulho de tiro com a boca e simula que o boneco estaria atirando.]

Dupla 2: Esse é o óculos solar. É melhor que todos os óculos do mundo, porque ele ajuda a ver melhor no sol. Mas os outros não têm a mesma vantagem que ele. O preço dele é muito bom: $\mathrm{R} \$ 23,90$. E parcelamos em duas vezes sem juros.

Dupla 3: Esse é o senhor patinho [faz barulho de pato com a boca]. Os amigos dele do orfanato estão precisando de uma ajuda. Você pode comprar ele por apenas $\mathrm{R} \$ 5,99$. Os amigos dele estão precisando de uma família no orfanato e ele também, sabia? Também pode servir muito para suas crianças abraçarem, pro seu cachorro morder... E só.

Nos anúncios criados pelas crianças, observamos a presença de um discurso informativo como atributo principal, com destaque para a informação sobre o preço dos produtos: "é muito barato", "o preço dele é muito bom", "apenas $\mathrm{R}$ \$ 5,99”. Também percebemos a presença de um discurso persuasivo, voltado para o convencimento à compra dos objetos anunciados. Como estratégias de persuasão, as crianças da dupla 2 recorreram às vantagens de uso do produto ("ajuda a ver melhor no sol") e as crianças das outras duplas fizeram uso do lado emocional ("se divertir em casa”, "os amigos dele do orfanato estão precisando de uma ajuda”). A utilização de efeitos especiais apareceu na dupla 1 , que indicou que o boneco de brinquedo se mexeria no anúncio e sairiam tiros explosivos da sua arma. Não houve qualquer menção a marcas em nenhum dos anúncios criados. 
Com essa atividade, foi possível mapear os conhecimentos prévios das crianças sobre publicidade, além de proporcionar um momento de reflexão sobre os anúncios a que são expostas diariamente. Para construírem suas peças, tiveram que recorrer ao que elas veem, às estratégias a que mais estão expostas. Ou seja, as crianças tiveram que pensar sobre o que é uma publicidade e acerca de quais são os possíveis elementos que a compõem, para depois organizarem todo esse conhecimento em um anúncio.

\subsection{Desmitificando a publicidade}

A segunda atividade da oficina teve como objetivo desvelar a função da publicidade, seu objetivo e suas estratégias de persuasão. Para tanto, com auxílio de apresentação de slides, trabalhamos com as crianças a partir de três questões-problema em torno da temática da publicidade: "para que serve?", "onde eu vejo?" e "como funciona?". Desse modo, seguindo esse roteiro, primeiramente problematizamos a atividade publicitária como forma de comunicação que se caracteriza pela persuasão e, portanto, tem sempre a função de despertar nas pessoas o desejo de adquirir algo. Posteriormente, discutimos a respeito da presença da publicidade em vários aspectos de nossa vida cultural e social, ou seja, em vários momentos da nossa vida cotidiana. O intuito era demonstrar que em diversos espaços há empresas tentando nos convencer a comprar ou a sentir vontade de comprar algo. Em seguida, apresentamos definições e exemplos de alguns dos elementos que compõem um anúncio, os quais contribuem para que uma marca se destaque e obtenha êxito junto a seu público-alvo. Entre esses elementos, destacamos:

- Logo: nome, sinal, desenho para identificar uma empresa.

- Slogan: palavra ou frase curta de fácil memorização.

- Jingle: música curta usada no comercial para divulgar um produto ou empresa.

- Mascote: animal, pessoa ou objeto animado que representa uma marca ou uma empresa.

- Uso de celebridades e personagens: presença de pessoas reconhecidas pelo público ou personagens do mundo de desenhos animados, filmes e histórias em quadrinhos.

24. REAL food, but not really: something savoury. 1'52". Mynhky Le. Vimeo. Disponível em: < https:// vimeo.com/111076177>. Acesso em: 20 jul. 2017; REAL food, but not really: something sweet. 1'37". Mynhky Le. Vimeo. Disponível em: < https:// vimeo.com/111076179>. Acesso em: 20 jul. 2017.
Por fim, ressaltamos que a publicidade, para atingir seus objetivos, faz uso de vários artifícios (efeitos especiais, técnicas de manipulação de imagens etc.). Com o intuito de evidenciar isso, exibimos exemplos que revelam o contraste flagrante entre o que aparece no anúncio e a realidade. Entre os vídeos mostrados às crianças para tal fim, estavam dois da série Real food, but not really ${ }^{24}$, criada por Minhky Le, os quais exploram como os alimentos são preparados para serem servidos e como são produzidos para fotografia 
ou vídeo publicitário, por meio do uso de corantes, enchimento de algodão, gelo artificial e uma série de outros mecanismos. Outro vídeo exibido foi o Evolution ${ }^{25}$, veiculado em 2006, no Canadá, como parte da campanha "Real beleza" da marca Dove. O vídeo denuncia como os efeitos de iluminação, maquiagem e manipulação digital aplicados para o desenvolvimento de um anúncio podem modificar profundamente as características de uma modelo e distorcer nossa percepção de beleza.

Durante a discussão, as crianças se mostraram interessadas e participativas, dando suas opiniões e relatando experiências do seu cotidiano. No momento da transmissão dos vídeos, demonstraram surpresa e estranheza em relação a alguns dos recursos usados pela publicidade. Sobre o vídeo da campanha "Real beleza”, alguns disseram: "Tão até botando cabelo. Nossa!"; "Eles tão botando pescoço"; "Caraca, eles botam tudo. Tudo é mentira”. Acerca dos vídeos da série Real food, but not really, falaram: "Caraca, meu. É pra fingir"; "Pra grudar né? Caraca! Algodão?"; "Aí a gente vê, fica com uma super fome, compra e vê que não era bem aquilo que a gente viu na propaganda", "E a gente tá querendo comer isso". Essas falas evidenciam a credulidade que essas crianças tinham na publicidade e até uma certa inocência diante dos vários artifícios possíveis de serem utilizados para tornar uma campanha mais atrativa aos olhos de quem irá consumi-la. Esse momento da oficina, portanto, possibilitou que as crianças avaliassem, e até desmistificassem, seus conhecimentos prévios sobre a publicidade.

\subsection{Analisando a publicidade: o que esse anúncio diz?}

A última atividade da oficina consistiu em propor que as crianças analisassem criticamente um anúncio publicitário. Para tanto, solicitamos que, organizadas em duplas, se atentassem para os seguintes aspectos: qual o produto vendido, qual a marca do produto, a qual público-alvo busca atingir, onde o anúncio pode ter sido divulgado e o que é usado como estratégia para chamar atenção do público-alvo.

Para a atividade de análise, cada dupla recebeu uma peça publicitária. Após a discussão, as crianças socializaram suas impressões para o restante do grupo. A dupla 1 ficou com um anúncio do produto Danoninho, da marca Danone. As crianças conseguiram identificar o produto anunciado, assim como a marca que o vendia. Disseram que o público-alvo era o infantil, mas não souberam explicar por quê. Uma criança de outra dupla ajudou-os, dizendo que o anúncio talvez fosse para criança por conta do uso do personagem Dino (dinossauro usual nas campanhas de Danoninho). Afirmaram que a peça deve ter sido veiculada em supermercados, próximo às prateleiras nas quais o produto é exposto, pois chamaria mais atenção. Quando indagados sobre quais estratégias de persuasão conseguiram identificar no anúncio, citaram o slogan ("tão saudável quanto um carinho") e o personagem Dino.
25. BELEZA. 1'00" Peterson Alves de Araujo. YouTube. 2013. Disponível em: <https:// www.youtube.com/watch? $=$ =URUuSB 4 b GpY> Acesso em: 20 jul. 2017. 
A dupla 2 analisou uma peça promocional de outro iogurte da marca Danone. As crianças identificaram tanto o produto como a marca. De acordo com elas, o comercial foi direcionado a "crianças de 2 a 8 ou 9 anos", pois crianças maiores não iriam se interessar por aquele produto. Revista e televisão foram os meios indicados como possíveis de ter veiculado aquela publicidade. Entretanto, quando a pesquisadora começou a apontar alguns elementos do cabeçalho e do rodapé da peça, que passaram despercebidos, as crianças mudaram de ideia e disseram que, na verdade, a peça foi veiculada na internet: "Ah, é na internet"; "Parece que já está na tela do computador"; “Tem o Facebook e tudo ali”. Entre as estratégias usadas para chamar atenção, foram citadas o uso de personagens da Turma da Mônica e a utilização de jogos para tornar o anúncio divertido e atrair as crianças.

Por sua vez, a dupla 3 teve a tarefa de analisar uma publicidade de produtos de maquiagem da marca O Boticário. Assim como ocorreu nos outros dois anúncios, as crianças conseguiram identificar o produto e a marca. Disseram que a peça deve ter sido veiculada em revistas, mas ressaltaram que já viram um comercial semelhante àquele na televisão. A questão sobre a que público-alvo a peça se destinaria gerou divergência. A dupla responsável pela análise afirmou que o anúncio se destinava a mulheres adultas, pois "[...] criança não quer não comprar esse produto". As outras crianças do grupo não concordaram. Uma das meninas argumentou haver criança que também usa maquiagem. Outra menina contra-argumentou, dizendo que crianças muito pequenas - com 3 anos, por exemplo - não utilizam esses produtos. Um dos meninos, com base na discussão levantada pelas colegas, disse que o público-alvo do anúncio poderia ser, então, meninas a partir de 9 anos. Por fim, como estratégias para chamar atenção, a dupla apontou o uso de uma modelo bonita, os efeitos de luz em seu rosto e o movimento dela passando o batom na boca. Todavia, o fato de a modelo ser uma atriz famosa entre os jovens passou despercebido pelas crianças.

Nessa atividade, portanto, as crianças dividiram, descontruíram a publicidade, a fim de visualizar os elementos que a compõem e buscar entender a função de cada um deles. Esse exercício possibilitou trabalhar algumas das habilidades de literacia publicitária propostas no modelo de Malmelin ${ }^{26}$, sobretudo, as dimensões estética/visual e retórica. Ademais, avaliamos que a atividade permitiu abordar os princípios fundamentais de $\mathrm{Baker}^{27}$, especialmente, no que tange à compreensão de que toda mensagem publicitária é criteriosamente construída para atingir um determinado público, por meio de uma linguagem criativa e persuasiva.

26. MALMELIN, Nando, op. cit.

27. BAKER, Frank W., op. cit.

\section{CONSIDERAÇÕES FINAIS}

Neste artigo, apresentamos e discutimos sobre uma experiência de oficina de leitura crítica da publicidade com crianças, a qual contribui para diminuir a lacuna das iniciativas sobre literacia publicitária, sobretudo voltadas ao público 
infantil. A oficina contou com três atividades que, em conjunto, deram a oportunidade de trabalhar as competências em literacia publicitária em três aspectos: organizar, avaliar e compreender. Nessa perspectiva, ao "brincarem de criar um anúncio", as crianças foram convidadas a organizar seus conhecimentos prévios sobre publicidade. Posteriormente, na atividade "desmistificando a publicidade", puderam avaliar alguns desses conhecimentos. Por fim, ao realizarem o exercício prático de análise de uma peça publicitária, puderam refletir sobre estética, linguagem e estratégias e, assim, compreender que todo anúncio é cuidadosamente criado por alguém, com algum objetivo, para atingir determinadas pessoas.

Compreendendo a educação para as mídias como uma discussão que também envolve os direitos das crianças, este estudo evidenciou a relevância de construir canais de diálogo para que as crianças possam expressar o que pensam sobre a publicidade e, sobretudo, possam aprofundar seu senso crítico sobre as relações de consumo que têm pautado a sociedade, além de possibilitá-las a tornarem-se difusoras dessas ideias entre seus pares.

Em um cenário como o brasileiro, no qual, à revelia de leis e resoluções vigentes no país, as marcas permanecem direcionando sua comunicação mercadológica às crianças, discutir acerca da educação para a recepção crítica infantil da publicidade é premente. Essa urgência se intensifica no contexto atual, em que a publicidade, mediada pelas tecnologias digitais, enfrenta um novo paradigma centrado em práticas cada vez mais lúdicas, interativas e hibridizadas com o entretenimento, as quais tendem a ser mais atraentes e envolventes para as crianças. Nesse sentido, em uma segunda etapa da pesquisa, expandiremos a experiência que aqui apresentamos focando em práticas de publicidade especificamente no ambiente on-line.

\section{REFERÊNCIAS BIBLIOGRÁFICAS}

ABREU, Belinha S. de. Media literacy, social networking, and the Web 2.0 environment for the K-12 educator. New York: Peter Lang, 2011.

BAKER, Frank W. Political campaigns and political advertising: a media literacy guide. Westport: Greenwood Press, 2008.

BELEZA. 1'00”. Peterson Alves de Araujo. YouTube. 2013. Disponível em: $<$ https://www.youtube.com/watch?v=URUuSB4bGpY>. Acesso em: 20 jul. 2017.

BÉVORT, Evelyne; BELLONI, Maria Luiza. Mídia-educação: conceito, histórias e perspectivas. Educação e Sociedade, Campinas, v. 30, n. 109, p. 1081-1102, set./dez. 2009.

BRASIL. Conselho Nacional dos Direitos da Criança e do Adolescente. Resolução no 163 , de 13 de março de 2014. Dispõe dobre a abusividade do direcionamento de publicidade e de comunicação mercadológica à criança 
e ao adolescente. Diário Oficial [da] República Federativa do Brasil, Brasília, DF, 4 abr. 2014. Disponível em: <http://www.crianca.mppr.mp.br/arquivos/ File/legis/conanda/conanda_resolucao_163_publicada.pdf $>$. Acesso em: 3 jan. 2018.

BURROWES, Patricia. Observatoryof expandedadvertising: an experiencewith advertising literacy workshops in Rio de Janeiro, Brazil. In: CONGRESSO DA INTERNATIONAL ASSOCIATION FOR MEDIA AND COMMUNICATION RESEARCH, 2017, Cartagena. Anais... Cartagena: IAMCR, 2017.

CASTRO, Lúcia Rabello de; BESSET, Vera Lopes. Pesquisa-intervenção na infância e juventude: construindo caminhos. In: CASTRO, Lúcia Rabello de; BESSET, Vera Lopes (orgs.). Pesquisa-intervenção na infância e juventude. Rio de Janeiro: Trarepa/Faperj, 2008. p. 9-12.

COVALESKI, Rogério. O exercício da cidadania na literacia das novas narrativas publicitárias. In: PEREIRA, Sara; TOSCANO, Margarida (eds.). Literacia, media e cidadania: livro de atas do $3^{\circ}$ congresso. Braga: CECS, 2015a. p. 456-467.

- Conteúdo de marcas e entretenimento: narrativas híbridas. Comunicação, Mídia, Consumo, São Paulo, v. 12, n. 34, p. 107-123, 2015b.

CRAVEIRO, Pâmela Saunders Uchôa. Publicidade e infância: estratégias persuasivas direcionadas para crianças na internet. Culturas Midiáticas, João Pessoa, v. 9, n. 1, p. 16-32, 2016.

FANTIN, Monica. Mídia-educação: aspectos históricos e metodológicos. Olhar de Professor, Ponta Grossa, v. 14, n. 1, p. 27-40, 2011.

GUEDES, Brenda; COVALESKI, Rogério. Publicidade e infância: traços de uma cultura infantil do consumo. In: ALCÂNTARA, Alessandra; GUEDES, Brenda. Culturas infantis do consumo: práticas e experiências contemporâneas. São Paulo: Pimenta Cultural, 2014. p. 153-177.

MACHADO, Monica; BURROWES, Patricia; RETT, Lucimara. Para ler a publicidade expandida: em favor da literacia midiática dos discursos das marcas. In: ENCONTRO ANUAL DA COMPÓS, 26., 2017, São Paulo. Anais... São Paulo: Associação Nacional dos Programas de Pós-Graduação em Comunicação, 2017. p. 1-15.

MALMELIN, Nando. What is advertising literacy? Exploring the dimensions of advertising literacy. Journal of Visual Literacy, Abingdon, v. 29, n. 2, p. 129142, 2010.

MARTÍ-PARREÑO, Jose. Marketing y videojuegos: product placement, ingame advertising y advergaming. Madrid: Esic, 2010.

MONTIGNEAUX, Nicolas. Público-alvo: crianças. Rio de Janeiro: Campus, 2003. 
REAL food, but not really: something savoury. 1'52". Mynhky Le. Vimeo. Disponível em: <https://vimeo.com/111076177>. Acesso em: 20 jul. 2017.

REAL food, but not really: something sweet. 1'37'. Mynhky Le. Vimeo. Disponível em: <https://vimeo.com/111076179>. Acesso em: 20 jul. 2017.

SCHOR, Juliet B. Nascidos para comprar: uma leitura essencial para orientarmos nossas crianças na era do consumismo. São Paulo: Gente, 2009.

SETTON, Maria da Graça. Mídia e educação. São Paulo: Contexto, 2015.

STEINBERG, Shirley; KINCHELOE, Joe (orgs.). Cultura infantil: a construção corporativa da infância. Rio de Janeiro: Civilização Brasileira, 2004. 
